\title{
Vivências de Sofrimento e Prazer no Trabalho de Gerentes de Banco
}

Experiences of Suffering and Pleasure in the Work of Bank Managers

Experiencias de Sufrimiento y Placer en el Trabajo de Gerentes de Bancos
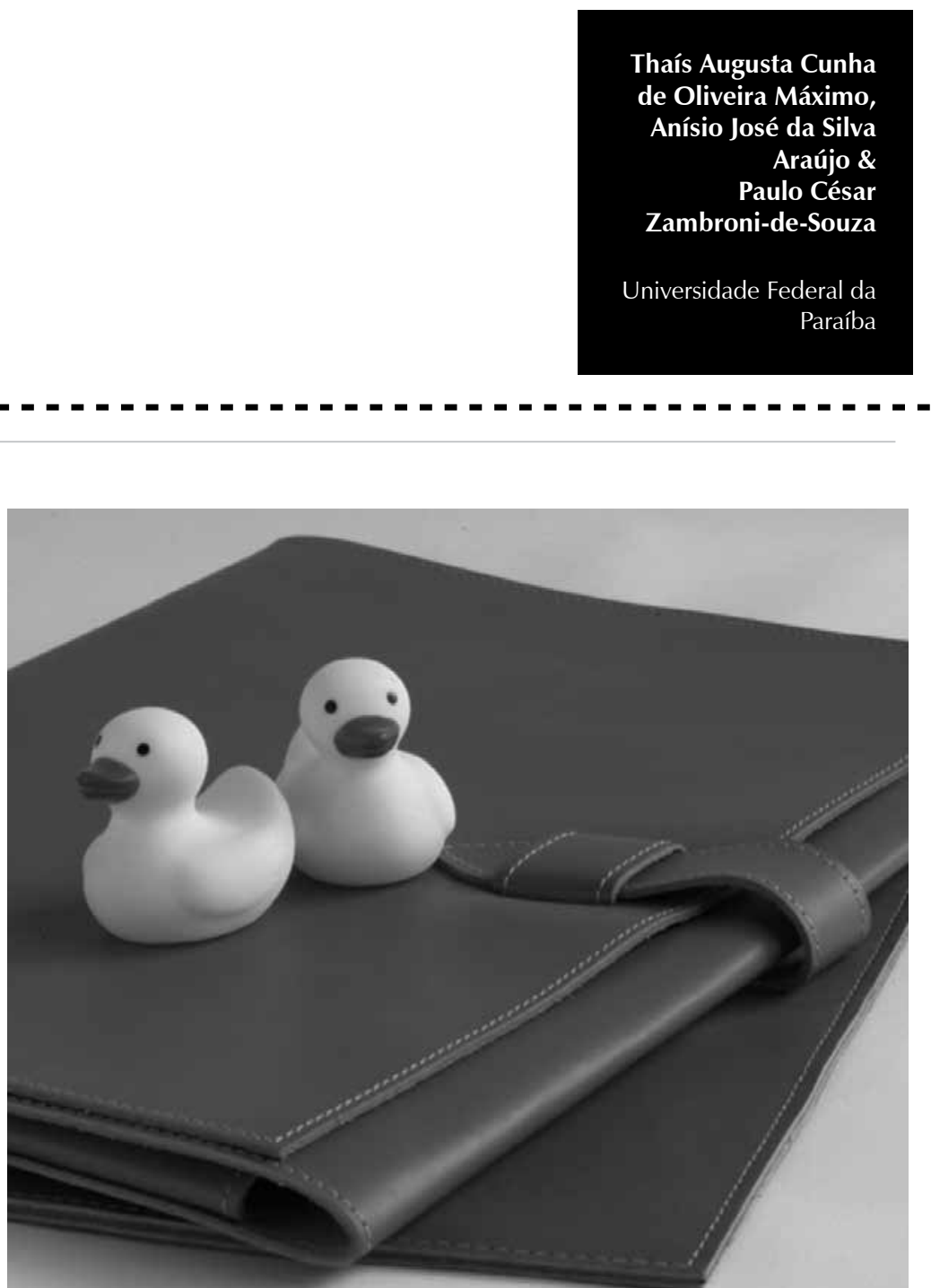
Resumo: Este artigo tem por objetivo discutir as vivências de sofrimento e prazer no trabalho de gerentes de bancos públicos e privados da cidade de João Pessoa, Paraíba. Para tanto, a psicodinâmica do trabalho foi utilizada como referência teórica principal, tendo em vista a articulação dos materiais produzidos em campo com o que a abordagem ensina sobre o sujeito no trabalho, especificamente no que diz respeito à relação complexa entre sofrimento, prazer e trabalho. Para as análises apresentadas, consideram-se as transformações no trabalho gerencial e nos modos de gestão e de funcionamento dos bancos ocorridos nas últimas décadas. Foram realizadas 16 entrevistas com pessoas que exerciam gerências gerais ou intermediárias, analisadas através da análise de conteúdo temática. Os resultados evidenciaram que os seguintes elementos se colocam como fonte de prazer ou de sofrimento: o trabalho com clientes e outros funcionários, o reconhecimento ou a ausência de reconhecimento desse trabalho, a estrutura organizacional, a carga de trabalho e a pressão por resultados, a autonomia ou a falta de autonomia para tomar decisões e a remuneração. Tais resultados demonstram que a relação entre a organização do trabalho e o sujeito está em contínuo movimento, em equilíbrio dinâmico.

Palavras-chave: Gerentes. Organização do trabalho. Sofrimento. Satisfação no trabalho. Stress ocupacional.

\begin{abstract}
That article aims to discuss the suffering and pleasure experiences in the work of public and private bank managers of João Pessoa-PB. Taking psycodynamic of work as main theoretical reference, it articulates the material produced in the field with the theory approach on the subjects' operation at work, specifically in what concerns the complex relationship among suffering, pleasure and work. For the presented analysis, the transformations in the managerial work and in the administration manners and the bank operations that happened in the last decades are considered. In the field research sixteen interviews were accomplished with people that exercised general or intermediate managements, analyzed through content analysis. The results show that the following elements can be sources of pleasure or suffering: working with customers and other employees, the recognition or the absence of recognition of this work, the organizational structure, the work load and the pressure for results, the autonomy or the lack of autonomy to take decisions, and the salary. Keywords: Managers. Work organization. Suffering. Satisfaction. Occupational stress.
\end{abstract}

Resumen: Este artículo tiene como objetivo analizar las experiencias de sufrimiento y placer en el trabajo de gerentes de bancos públicos y privados en la ciudad de João Pessoa, Paraíba. Para eso, este trabajo se utilizó de la Psicodinámica del Trabajo como referencia teórica principal, apoyándose en la articulación de los materiales producidos en campo, en la cual el abordaje teórico enseña sobre el funcionamiento del sujeto en el trabajo, sobre todo en lo que se refiere a la relación compleja entre sufrimiento, placer y trabajo. Para el análisis presentado se considera los cambios en el trabajo gerencial y en los modos de gestión y funcionamiento de los bancos que ocurrieron en las últimas décadas. Se realizaron dieciséis entrevistas con gerentes directos e intermediarios, las cuales fueron analizadas desde el análisis de contenido temático. Los resultados obtenidos evidenciaron que los siguientes elementos se presentan como fuente de placer o sufrimiento: el trabajo con los clientes y otros empleados, el reconocimiento o la ausencia de este, la estructura organizativa, la carga de trabajo y la presión por resultados, la autonomía para tomar decisiones o la falta de ella, la remuneración. Tales resultados demuestran que la relación entre la organización del trabajo y el sujeto está en continuo movimiento, en equilibrio dinámico.

Palabras clave: Gerente. Organización del trabajo. Sufrimiento. Satisfacción en el trabajo. Estres ocupacional.

Este artigo tem como objetivo analisar as vivências de sofrimento e de prazer no trabalho de gerentes de bancos públicos e privados da cidade de João Pessoa - PB. Este estudo é parte de uma investigação mais ampla sobre exigências nos percursos profissionais de gerentes de banco, que foi objeto da pesquisa de mestrado desenvolvida pela primeira autora (Máximo, 2009). No sentido de possibilitar a compreensão da temática, faz-se necessária a apresentação dos alicerces teóricos da psicodinâmica do trabalho (PDT) que se mostraram relevantes para a discussão dos dados produzidos no estudo. Posteriormente, será traçado um breve panorama das recentes transformações no trabalho bancário, destacando como elas se refletiram em novas demandas para os gerentes de bancos.

\section{A relação entre sofrimento, prazer e dinâmica do reconhecimento na abordagem da psicodinâmica do trabalho (PDT)}

A centralidade do trabalho para os sujeitos é um dado inquestionável para a psicodinâmica 
do trabalho (PDT), que é a perspectiva teórica tomada como referência neste estudo. Dejours (1992 como citado em Lacman, 2004) destaca o trabalho como mediador privilegiado entre o sujeito e seu meio social, admitindo-o como condição de acesso à cidadania, além de ser a forma como a subjetividade se inscreve nos âmbitos social, ético e político. Contudo, as relações que se estabelecem entre o sujeito e seu trabalho se mostram complexas, tendo em vista que, por um lado, acredita-se que o trabalho prejudique a saúde e cause sofrimento, mas, por outro, admite-se que ele possa ser uma fonte de saúde e de realização pessoal.

A PDT sempre reconheceu a importância que o trabalho possui para a construção da identidade e para a manutenção da saúde e do bem-estar. No entanto, para essa abordagem, os modos de investigar essa relação se transformaram ao longo do tempo, o que significou a passagem de uma concepção que tinha como objetivo primordial investigar o trabalho como condicionante dos distúrbios psíquicos para uma nova perspectiva alicerçada no reconhecimento de que a relação entre a organização do trabalho e o homem não é um bloco rígido, mas está em contínuo movimento, em equilíbrio dinâmico, em deslocamento constante (Dejours, 2004a).

Dessa forma, quando se coloca face a face o funcionamento psíquico e a organização do trabalho, descobre-se que certas organizações podem ser perigosas para o equilíbrio psíquico e podem desencadear fadiga, patologias e tensão (Dejours, Dessors, \& Desriaux, 1993). Todavia, apesar de o trabalho poder ser perigoso e causar sofrimento e doença, Dejours (1993) como citado em Lacman 2004) destaca que ele não é obrigatoriamente uma infelicidade, podendo, inclusive, ser estruturante para a identidade e a saúde. O prazer no trabalho refere-se, desse modo, conforme Alderson, "ao estado de bem- estar psíquico que conhece o trabalhador quando seu trabalho satisfaz seus desejos de reconhecimento, permitindo-lhe, assim, construir sua identidade" (2004, p. 250).

Dejours (2004b) postula que o sofrimento é algo dos humanos, e o trabalho, lugar de sublimação. Por isso, não se pode conceber uma organização do trabalho sem sofrimento. Nessa mesma linha, Alderson afirma que "a psicodinâmica do trabalho considera que o sofrimento é consubstancial a toda situação de trabalho, ou seja, é inerente à condição do homem no trabalho" (2004, p. 249).

Não obstante, existem organizações do trabalho que são mais favoráveis à negociação da superação desse sofrimento, enquanto outras se colocam como claramente patogênicas. Ferreira e Barros (2002) afirmam que é justamente o descompasso entre o que a organização de trabalho prescreve e as demandas e exigências reais enfrentadas pelo trabalhador que constitui fator gerador de sofrimento. Nesse sentido, quanto maior esse descompasso, maior o custo humano, potencializando as vivências de sofrimento patogênico. Quando essa discrepância se torna de difícil gestão, levando à repetição dos mesmos problemas e fracassos, configura-se uma situação desgastante do ponto de vista psíquico, com incidências na produtividade e na qualidade do trabalho.

Dejours, Abdouchelli e Jayet (1994) ressaltam que o sofrimento no trabalho não é necessariamente patológico, na medida em que pode funcionar como um sinal de alerta para evitar o adoecimento. Contudo, quando não há liberdade de negociação entre o sujeito e a organização do trabalho, e o trabalhador não consegue ressignificar seu trabalho, termina por desenvolver doenças, tanto físicas, quanto psíquicas.

O sofrimento chega a ser patogênico "quando todas as possibilidades de adaptação ou de 
Athayde (1996)

afirma que, no campo das relações sociais mediadas pelo trabalho, o par contribuição - retribuição é a chave para a mobilização subjetiva. Além do mais, o reconhecimento do fazer confere ao trabalhador avaliado um sentimento de pertença a um coletivo, a uma equipe ou a um ofício (Dejours, 2004c). ajustamento à organização do trabalho pelo sujeito, para colocá-la em concordância com seu desejo, foram utilizadas, e a relação subjetiva com a organização do trabalho está bloqueada" (Dejours, Abdouchelli, \& Jayet, 1994, p. 127). Em contrapartida, quando é possível enfrentar os constrangimentos por meio da mobilização da inteligência criativa, a saúde e o prazer podem ser conquistados, ainda que de forma instável, pois jamais serão definitivamente adquiridos.

Pode-se, assim, concluir que a saúde e o prazer consistem na busca, na luta, revelando-se quando a esperança e a criatividade são permitidas ao trabalhador, de maneira que o trabalho possa funcionar como um mediador de saúde (Silva \& Merlo, 2007). No dizer de Alderson, "o prazer no trabalho é o destino feliz do sofrimento no trabalho; ele é o prazer secundário quando a sublimação foi socialmente e eticamente possível" (2004, p. 250). Para que a sublimação alcance essa possibilidade e se torne sustentáculo do prazer e, em consequência, da saúde e da identidade, é fundamental a obtenção do reconhecimento no trabalho.

Na PDT, o reconhecimento desponta como um dos principais elementos na relação do sujeito com o trabalho. Constantemente, o trabalhador busca possibilidades de intervenção e de criação em seu meio e, em contrapartida, espera obter um retorno do seu investimento através do reconhecimento de suas ações em favor da organização do trabalho. Athayde (1996) afirma que, no campo das relações sociais mediadas pelo trabalho, o par contribuição - retribuição é a chave para a mobilização subjetiva. Além do mais, o reconhecimento do fazer confere ao trabalhador avaliado um sentimento de pertença a um coletivo, a uma equipe ou a um ofício (Dejours, 2004c).

O reconhecimento passa pela rigorosa construção de julgamentos sobre o trabalho, tanto por parte dos superiores (julgamento de utilidade) quanto dos pares (julgamento de beleza). Esses julgamentos são proferidos diretamente sobre o trabalho realizado, e não sobre o trabalhador, e envolvem, primeiramente, a conformidade às normas, às regras de ofício e aos laços de cooperação.

O reconhecimento da qualidade do trabalho realizado pode inscrever-se na esfera da identidade, visto que sofre a mediação do outro, que exerce o papel de juiz (Dejours, Dessors \& Derslaux, 1993). Outrossim, a construção de sentido do trabalho pelo reconhecimento pode transformar sofrimento em prazer. Se a dinâmica do reconhecimento não está presente, o sofrimento não pode mais ser transformado em prazer, e o trabalhador não mais encontra sentido no que faz (Dejours, Dessors \& Derslaux, 1993), por isso afirma-se que a relação do sujeito com seu trabalho não pode ser considerada a partir de um olhar unicausal, tendo em vista as nuances e as complexidades presentes na construção das relações e dos sentidos no trabalho.

\section{As novas demandas sobre os gerentes de banco}

Partindo dessa compreensão do trabalho como potencial fonte de prazer ou de sofrimento, e compreendendo que toda análise do trabalho precisa ser feita a partir de um olhar clínico, situado, faz-se oportuna uma breve contextualização acerca das transformações pelas quais o setor bancário passou e que atingiram diretamente os profissionais abordados neste artigo: os gerentes de banco.

Netz e Mendes (2006) ressaltam que a categoria bancária parece ser a que melhor reflete a condição moderna do desgaste humano no processo de trabalho, principalmente devido à introdução das novas tecnologias no setor, que ocasionaram uma profunda reestruturacão organizacional, tendo 
como efeitos: desemprego, terceirização, precarização e intensificação do trabalho, além da necessidade de constante atualização profissional. Diante desse quadro, ocorrem com os bancários problemas tanto da ordem da saúde mental quanto de lesões por esforços repetitivos (Borges, 2010; Maeno, 2011; Rossi, 2011).

As atuais formas de gestão passaram a focalizar uma nova maneira de atendimento aos clientes como forma de redução de custos e de aumento de lucratividade, ou seja, os próprios clientes passaram a executar grande parte das operações até então realizadas por funcionários, ficando o espaço das agências destinado sobretudo - mas não apenas - ao trabalho que depende da intervenção direta dos gerentes. Nesse cenário, o trabalho gerencial vai ganhando destaque, e um novo formato de trabalho vai apresentando-se a esses trabalhadores, situação em que a lógica da produtividade industrial e a lógica do serviço imbricam, gerando crescentes exigências para os trabalhadores (Tertre, 2011).

Nesse contexto, em que a flexibilidade ocupa um espaço cada vez maior, aliandose às novas tecnologias, resta ao trabalhador flexibilizar-se para atender as demandas. Assim, as transformações no trabalho bancário trouxeram, muitas vezes, "intensificação do trabalho e estabeleceram relações mais competitivas, superficiais e fundamentadas no individualismo e na flexibilidade" (Soboll, 2010, p. 358), o que pode impedir o estabelecimento da confiança entre os pares, elemento central para o estabelecimento da cooperação e fundamental para o desenvolvimento subjetivo e protetor da saúde no trabalho (Dejours \& Gernet, 2011). O novo trabalhador bancário configura-se, portanto, como aquele que responde afirmativamente e imediatamente a quaisquer demandas que se apresentem, caracterizando-se como protótipo de flexibilidade. Tais aspectos, sem dúvida, resultam em grande desgaste físico e mental da força de trabalho, que precisa diversificar sua atuação e intensificar os lucros sob a ameaça constante da perda de emprego, de tal forma que alcançar a produtividade custa muitas vezes sua saúde (Grisci \& Bessi, 2004; Maeno, 2011).

Jinkings (2002) reflete que o novo padrão imposto ao trabalhador pela reestruturação exige não somente a mobilização dos corpos mas também a mobilização total do indivíduo, não somente sua energia física mas também sua energia psíquica e afetiva. Assim, a polivalência do bancário e a sua habilidade em lidar com as tarefas não prescritas se tornam supervalorizadas, ou seja, dá-se importância ao saber prático do trabalhador (Larangeira, 1997), por isso, a absorção integral da pessoa pela organização em decorrência da complexidade, da diversidade e da dinâmica do mundo organizacional parece ser uma condição determinante para a execução do papel gerencial. A pressão psíquica para a obtenção de resultados é intensa, além do fato de que o fracasso no alcance das metas está diretamente relacionado a uma demissão imediata: sentem-se pressionados, pois temem a demissão (Almeida \& Merlo, 2008). Como afirma Sennett (1999), é a incerteza como regra que constrange os gerentes a um movimento sem tréguas, instalando uma ansiedade contínua. No caso dos gerentes, estão submetidos a grandes exigências quanto à capacitação, ao alcance de resultados e à disponibilidade para a empresa, ao mesmo tempo em que atender tais exigências não garante sua estabilidade na função (Máximo, Araújo, Zambroni-de-Souza, \& Alberto, 2011).

A vigilância não incide mais sobre os processos, mas sobre os resultados, o que aumenta a liberdade em relação às tarefas a cumprir. Em contrapartida, crescem as exigências sobre o cumprimento das metas e dos resultados pré-estabelecidos pela empresa, e o sujeito 
vê a fronteira entre trabalho e vida pessoal tornar-se cada vez mais frágil, já que o tempo e o espaço de trabalho se tornam ilimitados. E é desse modo que o controle minucioso da atividade vai dando lugar aos dispositivos de mobilização e de responsabilização dos sujeitos sobre os objetivos organizacionais (Gaulejac, 2007).

\section{Método}

Para esta pesquisa, fez-se uso de uma abordagem qualitativa, em razão do interesse em uma aproximação das experiências subjetivas dos gerentes de banco, buscando com eles decifrar o caráter sempre enigmático do trabalho e do prazer e/ou sofrimento ali vivenciado, utilizando-se da estratégia dialógica como meio de construção de conhecimento sobre as vivências do e no trabalho.

\section{Participantes}

Participaram deste estudo 16 gerentes de cinco bancos privados (Pv) e de dois bancos públicos (Pub). Desse total, sete ocupavam a função de Gerente Geral (GG), três eram Gerentes de Relacionamento de Pessoa Física (GPF), três eram Gerentes de Atendimento (GAT), dois eram Gerentes de Relacionamento de Pessoa Jurídica (GPJ) e um era Gerente Administrativo (GA).

Dentre os participantes, 15 são do sexo masculino e apenas um é do sexo feminino. As idades variaram entre 28 e 47 anos, com média de 38 anos. Quanto ao estado civil, 13 gerentes são casados, dois são divorciados e um é solteiro. No tocante à quantidade de filhos, a maioria dos entrevistados possui dois filhos.

\section{Instrumento}

Como instrumento para construção de dados, optou-se por um roteiro de entrevista semi- estruturada, pois sua flexibilidade favorece um contato mais próximo entre pesquisador e protagonista do trabalho. Alves-Mazzotti e Gewandszanajder (2002) destacam que, por seu caráter interativo, a entrevista possibilita o acesso a temas complexos, explorando-os em profundidade, isso porque, na entrevista, o investigador está interessado em compreender o sentido que o sujeito atribui aos temas relacionados ao objeto de estudo.

As questões da entrevista foram elaboradas a partir da abordagem teórica que fundamenta o nosso estudo, e versam sobre os seguintes temas: atividade, organização do trabalho, relações com os colegas, clientes e chefias, tensões e contradições vivenciadas, prazer e sofrimento no trabalho, condições de trabalho e aspectos da saúde física e mental.

\section{Procedimento}

A estratégia de definição dos entrevistados foi do tipo bola de neve, ou seja, o processo de pesquisa iniciou-se com alguns gerentes indicados pelo Sindicato dos Bancários, na cidade de João Pessoa - PB, que, por sua vez, se desdobraram em outras indicações. As entrevistas, realizadas no período de maio a dezembro de 2007, foram encerradas tendo como critério a saturação, que, segundo Minayo (2006), pode ser operacionalmente definida como a parada na inclusão de novos participantes quando os dados obtidos passam a apresentar, na avaliação do pesquisador, certa redundância ou repetição.

Apesar de Dejours (2004d) ressaltar a importância de, em psicodinâmica do trabalho, serem realizadas pesquisas com grupos homogêneos e coletivos de trabalhadores, a constituição desses grupos tornou-se inviável no presente estudo tendo em vista as especificidades apontadas acerca do trabalho gerencial, por isso as entrevistas foram realizadas individualmente. 
Das 16 entrevistas realizadas, apenas 3 foram agendadas dentro do horário em que o banco estava aberto ao público, a pedido dos próprios participantes. As demais aconteceram antes da abertura ou após o fechamento das agências. Quanto ao local de realização da entrevista, apenas uma se deu fora do ambiente de trabalho, em uma sala na Universidade Federal da Paraíba. Todas as outras tiveram como lócus o banco, na própria mesa dos gerentes ou em salas mais reservadas, a critério do entrevistado. A duração média das entrevistas foi de 45 minutos.

A participação de todos os sujeitos levou em consideração os aspectos éticos pertinentes à investigação que envolve seres humanos, conforme a Resolução no. 196/96, do Conselho Nacional de Saúde.

\section{Análise dos dados}

Para análise dos dados construídos, utilizouse da análise de conteúdo temática, que possibilitou uma interpretação sistemática dos relatos dos participantes do estudo e organização e visibilidade dos elementos construídos nas entrevistas. Segundo Laville e Dionne, essa análise "consiste em desmontar a estrutura e os elementos do conteúdo para esclarecer suas diferentes características e extrair sua significação" (1999, p. 214). Optou-se pelo recorte de conteúdo a partir de temas, ou seja, selecionaram-se trechos dos depoimentos de acordo com suas similaridades ou particularidades, e compuseram-se os chamados núcleos de sentido. Os critérios para estabelecimento das categorias foram a presença dos temas e a sua relevância para a compreensão do objeto como um todo.

\section{Resultados e discussão}

Em face do objetivo deste artigo, ou seja, discutir as vivências de sofrimento e prazer no trabalho de gerentes de bancos públicos e privados da cidade de João Pessoa, dos relatos dos participantes, emergiram seis categorias temáticas: realização, falta de reconhecimento, posição do gerente na estrutura organizacional, carga excessiva e pressão por resultados, autonomia ou falta de autonomia e remuneração. Utilizam-se legendas entre parênteses no final de cada depoimento, que correspondem ao número atribuído ao participante em função da ordem em que fora entrevistado, à função desempenhada e ao tipo de banco em que trabalha, que seguem o mesmo padrão da legenda proposta na seção Método.

\section{Realização}

Dejours (1994) destaca que não se pode conceber uma organização de trabalho isenta de sofrimento. Contudo, a saúde e o prazer podem ser conquistados quando se mostra possível a superação dos constrangimentos organizacionais, através da mobilização da inteligência astuciosa do trabalhador. Nesse sentido, a saúde, o prazer no trabalho, a realização de si mesmo e a construção da identidade são ganhos decorrentes do enfrentamento e da superação do sofrimento no trabalho.

Essa vivência conflituosa entre o prazer e o sofrimento na atividade é ilustrada por um dos gerentes ao afirmar que o "gerente é um carregador de piano, mas que, de vez em quando, ele senta e toca um pouquinho piano. Então assim, os desafios são grandes, as metas são sempre maiores, (...) mas é muito gratificante também" (16, GAT, Pub).

Em outros termos, por mais que existam dificuldades, pressão e sobrecarga, há paralelamente algo que confere ao trabalho um lado prazeroso, que faz com que a pessoa se mobilize para a concretização de sua atividade. No caso do trabalho gerencial, esse prazer se extrai do fato de em seu trabalho 


...como declara
Dejours, "para
trabalhar, é
necessário
também viver
junto, (...) porque
todo trabalho
engaja o corpo,
a inteligência, as
instituições, o ser
humano no que
ele tem de mais
íntimo" (1994, p.
31 1), e, se faltar
esse sentido, a
possibilidade de
uma doença
mental ou
psicossomática
aumenta.

ter sempre a presença de outros, funcionários ou clientes, como se verá posteriormente neste artigo. É necessário que o sujeito esteja envolvido com o trabalho e que este possua sentido, pois, como declara Dejours, "para trabalhar, é necessário também viver junto, (...) porque todo trabalho engaja o corpo, a inteligência, as instituições, o ser humano no que ele tem de mais íntimo" (1994, p. 311), e, se faltar esse sentido, a possibilidade de uma doença mental ou psicossomática aumenta.

O sentido do trabalho para os gerentes decorre, principalmente, do reconhecimento vindo dos outros, incluindo os clientes e a própria sociedade. Os participantes da pesquisa foram unânimes em apontar o atendimento aos clientes como a principal fonte de prazer do seu trabalho. Para usar a metáfora apresentada acima por um participante da pesquisa, carregar e tocar piano, nesse caso, faz-se sempre em orquestra e com uma plateia participativa.

Ferreira e Barros (2003) afirmam que o sujeito vivencia prazer quando consegue visualizar os resultados de sua produção. No caso dos gerentes, isso ocorre, principalmente, por meio do feedback dos clientes. Dentre as vivências de prazer, um destaque foi dado à possibilidade diária de ajudar inúmeras pessoas, realizando seus sonhos, resolvendo seus problemas e atendendo suas necessidades. Como afirma um dos gerentes gerais:

(...) Eu encontro uma satisfação muito grande porque tenho a oportunidade de contribuir, com o cliente de pessoa física, realizar seus sonhos, ajustar a sua vida; com o cliente de pessoa jurídica, a realizar seus projetos, projetos que vão ajudar aos funcionários, que vão ajudar a comunidade como um todo; aos colaboradores da empresa, porque tenho oportunidade de estar passando experiência, de estar orientando, de participar do sucesso deles e do crescimento deles. E à empresa, porque contribuo com os resultados, e essa empresa mantém os colaboradores (05, GG, Pv).
Como dito anteriormente, Dejours (2004b) assinala que a construção do sentido do trabalho se dá pela via do reconhecimento, capaz de transformar o sofrimento em prazer. O autor ressalta que a significação humana da tarefa e sua valorização social repercutem diretamente no sentimento de cada um por seu próprio trabalho. Um dos participantes afirma que, no seu caso, por trabalhar em um banco público, o fato de tal banco possuir a função social de financiar projetos ligados às políticas sociais do Governo coloca-se para ele como especialmente recompensador e prazeroso.

Apesar de os bancos públicos serem também movidos pela busca de lucratividade, existem, nesse caso, diferenças importantes, tais como: a possibilidade de praticar taxas de juros abaixo daquelas vigentes no mercado e a gestão de programas sociais governamentais que possuem desde taxas de juros subsidiadas até a concessão de empréstimos a fundo perdido. Enfim, o alcance social dessas ações de Governo, presentes em bancos públicos, contribuem para injetar sentido à atividade dos gerentes de banco.

Por outro lado, o aspecto relacional que marca essa atividade, o lidar com as pessoas, traço característico de um setor (o terciário) que vem ampliando-se consideravelmente nos últimos tempos, testemunha uma revolução no modo de organização do trabalho bancário, no qual o contato com o público no máximo se fazia através dos caixas executivos. É, portanto, toda a comunidade bancária que volta o seu olhar e atenção para o cliente, o que implica profunda reformulação organizacional, cujo objetivo é retirar o foco de qualquer outro fator que não seja o destinatário dos serviços bancários.

Se a atividade desenvolvida é provida de sentido para aquele que a desenvolve, as dificuldades enfrentadas não carregam o peso que teriam em outro contexto, 
onde a atividade é pouco significativa. As dificuldades do trabalho, nesse caso, apesar de não perderem a sua carga, são enfrentadas com a energia que o sentido do trabalho provê.

(...) A atividade em si que me dá prazer, mesmo tendo todos esses ranços (...); lidar com as pessoas é uma coisa que me dá muito prazer de uma maneira geral. No que pese a gente ter todas essas dificuldades, mesmo num dia muito cheio, muito ruim, com muita coisa negativa, você tem a possibilidade, todos os dias, em suas mãos, de fazer alguma coisa por alguém. E essa é uma característica que só esse banco tem, porque tem um lado social muito forte (03, GPF, Pub).

Por outro lado, as conquistas de sua equipe são descritas como fontes de prazer. Nesse caso, o sentido do trabalho relaciona-se a ensinar seus funcionários, auxiliando em seu desenvolvimento pessoal e profissional, como pode ser visto no trecho a seguir:

Uma coisa que me dá muito prazer é ver o crescimento das pessoas que estão trabalhando comigo, (...) poder atuar no desenvolvimento das pessoas, ajudá-las também a crescer (06, GG, Pv).

Como se defende nesse artigo, o prazer pode advir do enfrentamento de uma situação difícil, no momento em que o trabalhador consegue superar os obstáculos que se apresentam. Por outro lado, o sofrimento se faz presente, por vezes de maneira intensa, quando não é possível superar os obstáculos. Tanto é assim que justamente o que foi colocado como fonte de prazer pode consistir também em fonte de sofrimento, como se verá nos itens a seguir.

\section{A falta de reconhecimento: o outro como fonte de sofrimento}

A falta de reconhecimento por parte dos superiores, dos clientes e dos demais funcionários foi elencada como fonte de sofrimento pelos gerentes. Souza (2007), em sua pesquisa com operadores de caixas em um banco público, também identificou o convívio com os clientes como possível gerador de sofrimento e prazer, mostrando a contradição presente na condição humana no trabalho, pois o contato com os clientes se afigura ora como fonte de prazer, ora de sofrimento.

Para Dejours (2004b), quando a dinâmica do reconhecimento é paralisada, o sofrimento não mais se transforma em prazer, o que impede a elaboração de sentido pelo trabalhador e pode resultar em estados de descompensação psíquica ou somática. Um GG afirma que um dos momentos em que se sente mais frustrado é quando falta o reconhecimento dos superiores hierárquicos, o que pode ser constatado no depoimento a seguir:

Eu não gostaria de ser gerente titular quando eu me sinto frustrado que o meu superior não viu ou a empresa não reconheceu algum trabalho feito, ou alguma coisa nesse sentido, que eu acredito que deveria ser apoiado. Aí sim, eu fico superchateado de ser gerente naquele momento $(05, \mathrm{GG}, \mathrm{PV})$.

Ao gerente, pelo fato de se encontrar em um lugar privilegiado, ao qual corresponde um acréscimo de responsabilidades mas também melhor remuneração, além de outros privilégios, paradoxalmente muitas vezes não se oferecem algumas formas de reconhecimento. É como se a organização já o brindasse com uma posição superior, dispensando-se, portanto, outros retornos positivos através de palavras de alívio. O que o depoimento anterior evoca é que os gerentes precisam de reconhecimento, tal como os demais sujeitos, para injetar sentido ao trabalho e poder realizar a metamorfose do sofrimento em prazer. Desse modo, esse é um aspecto do qual a gestão não pode descuidar-se, especialmente porque sobre essa minoria, a dos gerentes, depositam-se 
muitas responsabilidades, especialmente aquela de manter a sua equipe empenhada no trabalho. A omissão, nesse caso, pode ter um efeito negativo multiplicado sobre os resultados organizacionais.

Outra vivência que causa sofrimento aos gerentes é a visão negativa que a sociedade tem dos bancos e que se reflete diretamente na imagem que as pessoas elaboram dos gerentes. Os participantes relataram que muitas pessoas não conseguem distinguir entre empresa e gerente, o que faz com que transfiram aos gerentes todo sentimento negativo acerca da instituição bancária, através de agressões verbais e atitudes intempestivas. Tais ocorrências trazem sofrimento aos gerentes, que chegam até mesmo a questionar o sentido do seu trabalho, como atesta o depoimento a seguir:

(...) Você trabalhar em banco hoje, realmente é muito malvisto pela sociedade. (...) O banco tem uma imagem muito ruim, e é passada pra gente. (...) Tem dia que a gente tem que escutar muita coisa: 'Ah, vocês são ladrões', isso, aquilo outro. Então, isso é ruim, é o lado negativo de trabalhar. Quando chega um dia desses que você está atendendo bem, ainda fica ouvindo um monte de coisa e a gente não pode revidar. (...) Então esses dias são os dias ruins, que a gente pensa: 'Ah, será que é isso que eu quero para o resto da minha vida, viver assim?' (06, GG, Pv).

Além da incompreensão que por vezes vem da sociedade, os participantes assinalaram que um relacionamento entre pares e/ ou com sua equipe, que foi colocado como fonte de prazer em determinados momentos, em outros, pode constituir motivo de sofrimento. Isso ocorre quando há discussões, brigas, resistência dos funcionários em aprender a lidar com novas situações e falta de compromisso com relação ao atendimento aos clientes. Há um esforço dos gerentes em orientar sua equipe, e sofrem quando percebem que não há interesse ou reconhecimento por seu trabalho.

\section{A posição do gerente na estrutura organizacional e o colocar-se no lugar do outro}

Se, por um lado, ocupar a posição de gerente na estrutura organizacional permite uma série de realizações, a tarefa de indicar quem será demitido e de proceder a essa demissão é fonte de grande desgaste. Assim, em virtude desse contexto de instabilidade no emprego, os gerentes, particularmente os de bancos privados, apontaram as demissões como os momentos de maior sofrimento em sua atividade.

Por um lado, a demissão gera sofrimento porque o gerente sabe que o funcionário que está sendo demitido tem família, projetos e precisa do emprego; por outro, a demissão traz à tona o sentimento de instabilidade no próprio gerente, pois este confrontase com a possibilidade de, um dia, ele mesmo vir a perder o emprego. Segundo Selligmann-Silva (1994), o processo de adoecimento e os reflexos psicossociais do desemprego começam a partir do momento em que o trabalhador percebe o risco de ficar desempregado. Um dos gerentes afirma que

(...) É difícil, porque você se coloca no lugar. Eu procuro também me colocar na situação do outro. Demitir funcionário é horrível, horrível, horrível. (...) Eu fico analisando um por um, futuramente pode ser eu. Isso é a coisa que eu acho mais difícil, você desligar um colega de trabalho (08, GG, Pv).

Dejours (2000) e Dejours e Bégue (2010) afirmam que, diante de tal pressão, muitos gerentes acabam por desenvolver descompensações na saúde ou acabam por aderir ao que aqueles autores chamam de banalidade do mal, isto é, promover ações que geram grande sofrimento aos seus subordinados em nome da sobrevivência e do crescimento da empresa, sem que se sintam mal com isso. 
A organização do trabalho é indicada por Dejours, Dessors e Derslaux (1993) como decisiva para o equilíbrio psíquico. Os autores afirmam que as organizações inflexíveis, que não deixam espaço para que o trabalhador possa organizar e adaptar a atividade às suas necessidades psíquicas e corporais, são geradoras de tensão e de desprazer. Os participantes destacaram como fontes de sofrimento alguns aspectos decorrentes da organização do trabalho, tais como o excesso de trabalho, tanto no que se refere à quantidade de horas trabalhadas quanto à intensificação e à sobrecarga, à pressão por resultados, às decisões que não dependem diretamente deles e às falhas no sistema do banco.

\section{A carga excessiva e a pressão por resultados}

Nos discursos dos gerentes, emergiu com frequência a dificuldade em lidar com uma carga horária ao mesmo tempo extensa e intensa. Os participantes relataram que a quantidade de horas trabalhadas gera sofrimento, desgaste e diminui as possibilidades de convivência familiar. Como a atividade gerencial é pautada em demandas, eles questionam o fato de não haver um limite na jornada. Um dos gerentes afirma que:

Embora a gente seja gerente, somos sacrificados porque não temos uma carga horária específica. Não pode dizer: 'Pronto, chegou minha carga horária e eu não trabalho mais'!, porque depende ou do dia ou da demanda (04, GG, Pub).

As palavras: penoso, desgastante, angustiante e frustrante apareceram associadas às situações de excesso de pessoas na agência e a grande volume de trabalho, agravadas pela falta de estrutura e insuficiência de pessoal, como observa um dos gerentes:

(...) Não é um super-homem para atender quatro ou cinco ao mesmo tempo. (...)
Eu às vezes me angustio um pouco, mas a gente tem que saber lidar com isso também. Queria ser o multi-homem, múltiplo, mas como não é possível, a gente tem que administrar isso aí (16, GAt, Pub).

Tal sobrecarga está relacionada com a reestruturação nos bancos que teve início nos anos 80 e que representou redução de custos operacionais por meio do fechamento de agências, demissões progressivas de funcionários e terceirização de diversas atividades (Jinkings, 2002; Merlo \& Barbarini, 2002; Bruno, 2011). O período que vai do final dos anos 80 até meados da década de 90 foi de importante redução do número de empregados nos bancos.

No tocante à pressão por resultados, muitos gerentes mencionaram as cobranças demasiadas como fontes de sofrimento do trabalho gerencial, pois, na atual conjuntura do mundo do trabalho, há pouco espaço para falhas, que podem ser punidas até mesmo com a demissão. Nesse sentido, um dos gerentes admitiu que o que lhe causa mais sofrimento é "quando eu não consigo cumprir uma meta. Isso pra mim, assim, eu não gosto. Como a gente é sempre acostumado a ganhar, a gente não costuma perder, quando a gente perde, a gente sofre" (07, GG, Pv), de onde se conclui que, em face da disseminação de um modo de gestão por metas que coloca o emprego continuamente em risco, perder transforma-se em fonte de sofrimento, e competir e vencer, em fonte de prazer e de realização.

Um GG concorda que o estresse é algo comum na atividade gerencial:

Na verdade, essa atividade bancária é uma atividade muito estressante. Isso aí realmente é o que pesa. Porque como eu te digo, a gente lida com dinheiro e com pessoas, então esse estresse é que dificulta muito a vida da gente (10, GG, Pub). 
A autonomia, ou a falta de autonomia

Outro elemento mencionado como possível causador de adoecimento psíquico são as impossibilidades de tomar certas decisões. Os gerentes destacaram que uma das coisas que mais lhes causa pesar é dar uma resposta negativa a um bom cliente tomando por base uma prescrição do banco com a qual ele não concorda plenamente, ou seja, são decisões sobre as quais eles não têm nenhuma interferência. No trecho a seguir, um GPF se pronuncia sobre essa questão:

O que me faz sofrer são as coisas as quais eu não posso ter influência, as que eu não tenho influência, as que eu respondo por elas solidariamente, mas não tenho influência. Dar as respostas negativas, principalmente por conta das coisas que eu não tenho gestão, é o que mais me maltrata, sabe!? Eu ainda estou aprendendo a lidar com isso. Tentando melhorar minha convivência com isso, porque, se você não conseguir, tende à tarja preta (03, GPF, Pub).

Tal observação corrobora o fato de que uma das características tidas como positivas no trabalho gerencial é a relativa autonomia de que ele goza. Logo, as barreiras a essa autonomia manifestam-se como fonte de sofrimento.

As falhas no sistema de informática dos bancos, que impõem sérios limites à autonomia gerencial, também foram apontadas como fontes de sofrimento em virtude dos transtornos que causam diante dos clientes e, principalmente, porque a resolução daquele problema não depende diretamente do gerente. Os gestores afirmaram que a maioria das pessoas não compreende que sua operação não pode ser efetuada sem o sistema, e quer que o problema seja resolvido de qualquer forma. Um GG destaca que "o pessoal pensa que o gerente tem uma varinha mágica, que vai lá e ajeita. Infelizmente, não ajeita. Não é nem só esse fato em si, mas é que acumula muita gente, (...) são os pepinos que a gente não quer" (04, GG, Pv).

\section{A remuneração}

Uma fonte de prazer destacada pelos gerentes foi a remuneração. De maneira geral, os gerentes relataram que se sentem satisfeitos com seu salário, em comparação com a média dos salários pagos na cidade de João Pessoa. Alguns deles afirmaram que é muito prazeroso ter um emprego capaz de suprir as necessidades de sua família e saber que os ganhos financeiros são fruto do seu trabalho, mesmo que, para isso, ele precise sacrificar a convivência com sua família.

Entendemos que a remuneração fornece não apenas os meios materiais para sobrevivência e consumo, mas reflete também o reconhecimento oferecido pelo empregador ao trabalho realizado, revelando o que, em suma, foram identificados como principais fontes de prazer no trabalho gerencial: o reconhecimento por parte dos pares, dos clientes, da sociedade como um todo e da organização do trabalho, sendo esta última mencionada através do salário, mas que certamente não se limita a ele. A colocação a seguir, feita por um dos gerentes, sintetiza a importância desse reconhecimento: (...) o que me dá mais prazer em meu trabalho é o reconhecimento. Você ser reconhecido pelos seus pares e pelos seus clientes, os elogios, enfim, isso é o que me dá mais prazer (12, GPF, Pv).

\section{Considerações finais}

A investigação sobre as fontes de sofrimento e prazer no trabalho revelou-se, na presente pesquisa, uma via importante para compreender por dentro como os gerentes enxergam diversos aspectos do seu trabalho. Nesse sentido, pode-se afirmar, já de início, que as direções dos diversos bancos podem 
"(...) O trabalho não é neutro com relação

à saúde, e favorece seja a doença, seja a saúde" (Dejours, 1992, p. 164). encontrar, nesse tipo de pesquisa, importantes materiais para formular ou reformular suas políticas organizacionais, ajustando-as às demandas e às necessidades humanas. Igualmente, as áreas do conhecimento que se voltam para o trabalho, como a Psicologia do trabalho e organizacional, a Sociologia do trabalho e a Administração de Empresas, dentre outras, podem beneficiar-se dos materiais aqui produzidos a fim de melhor compreender os sujeitos no trabalho.

Algumas das fontes de prazer apontadas testemunham a revolução organizacional pela qual passaram os bancos, em função da dimensão que o setor financeiro alcançou no capitalismo e do incremento da concorrência interbancária. Destacam-se, dentre estas, a atenção ao cliente e o lugar central que este passou a ocupar na nova arquitetura organizacional.

O bancário, em especial o gerente, foi, então, retirado da retaguarda, da penumbra, e colocado na linha de frente, sob a luz do contato com o cliente, e, nesse movimento, os gerentes assumem importante lugar para o funcionamento da nova lógica produtiva. Essa proximidade dos sujeitos, com a diversidade que os caracteriza, a possibilidade que esse encontro oferece de mergulhar na intimidade de suas angústias, de seus projetos e poder, ainda que com capital alheio, oferecer alternativas para encaminhamento de suas vidas, humanizou, de certo modo, o trabalho bancário, tão identificado que era com a burocracia, a rotina, o hábito, a mesmice. Ao mesmo tempo, como tudo tem o seu anverso, esse fato trouxe problemas, dificuldades, já que o atendimento ao cliente deve fazer-se sob a imposição de metas muito precisas, que contradizem, muitas vezes, a necessidade de personalizar esse atendimento, com a atenção que deve ser dispensada às suas expectativas.
As metas muitas vezes abusivas estabelecidas pelos bancos, expressão que chega a figurar na pauta de reivindicações dos sindicatos dos bancários, constitui um constrangimento organizacional da maior importância. Isso não corresponde a uma posição dos autores deste artigo, contrária ao estabelecimento de metas, prática tão decisiva na vida profissional e pessoal. O que se questiona são as metas abusivas, aquelas que solicitam os sujeitos, de forma contínua, para além de suas possibilidades, que podem ser responsáveis por muitos problemas de saúde, já que “(...) o trabalho não é neutro com relação à saúde, e favorece seja a doença, seja a saúde" (Dejours, 1992, p. 164).

A questão da falta de reconhecimento foi também destacada como uma fonte importante de sofrimento. Poder-se-ia pensar, a princípio, que essa questão não estaria colocada no caso do trabalho gerencial. Afinal, o gerente já se situa em um lugar privilegiado, outorgado pela organização, o que em si já constituiria uma expressão de reconhecimento suficiente. O que os relatos refletem é que os sujeitos desejam que sua contribuição seja visibilizada, apontada, gratificada. Esse é um aspecto importante, já que, sob os gerentes recaem muitas responsabilidades, particularmente aquelas de estimular, de atrair a equipe para um objetivo comum.

Enfim, a exploração das fontes de sofrimento e de prazer é uma via privilegiada de acesso à relação que cada um estabelece com o seu trabalho, um meio de autoconhecimento para o trabalhador, nesse caso, o gerente, e uma base para uma intervenção no sentido de favorecer o prazer no trabalho.

Esta pesquisa apresenta a limitação de ter sido realizada em apenas um Município brasileiro e com número limitado de participantes e bancos, de tal modo que se sugere a realização de investigação semelhante 
em outros Municípios brasileiros, com número maior de gerentes de vários bancos. Entende-se também que, em investigações futuras, pode-se fazer um comparativo entre os resultados produzidos com gerentes de bancos públicos e aqueles de bancos privados, a fim de melhor evidenciar se há diferenças nas vivências entre os dois grupos. 


\section{Thaís Augusta Cunha de Oliveira Máximo}

Doutora em Psicologia Social pela Universidade Federal da Paraíba. Docente do Departamento de Psicologia da Universidade Federal da Paraíba, João Pessoa - PB - Brasil.

E-mail: thaisaugusta@gmail.com

\section{Anísio José da Silva Araújo}

Doutor em Saúde Pública pela Fundação Oswaldo Cruz. Docente do Departamento de Psicologia / Programa de Pós-graduação em Psicologia Social da Universidade Federal da Paraíba, João Pessoa - PB - Brasil.

E-mail: anisiojsa@uol.com.br

\section{Paulo César Zambroni-de-Souza}

Doutor em Psicologia Social pela Universidade do Estado do Rio de Janeiro. Docente do Departamento de Psicologia / Programa de Pós-graduação em Psicologia Social da Universidade Federal da Paraíba, João Pessoa - PB - Brasil E-mail: paulozamsouza@yahoo.com.br

\section{Endereço para envio de correspondência:}

Departamento de Psicologia, UFPB campus Cidade Universitária, Conjunto Castelo Branco. CEP: 58059-900. João Pessoa, PB.

Recebido 03/08/2011, 1a Reformulação 02/07/2013, Aprovado 29/08/2013.

\section{Referências}

Alderson, M. (2004). La psychodynamique du travail: Objet, considerations épistémologiques et premisses théoriques. Santé mentale au Québec, 29(1), 243-260.

Almeida, L. L., \& Merlo, A. R. C. (2008). Manda quem pode, obedece quem tem juízo: prazer e sofrimento psíquico em cargos de gerência. Cad. Psicol. Soc. Trab. (online), 11(2), 139-157. Recuperado em 17 de fevereiro de 2011 de http://pepsic.bvsalud.org/pdf/cpst/v11n2/a02v11n2.pdf

Alves-Mazzotti, A. J., \& Gewandszanajder, F. (2002). O método nas ciências naturais e sociais: pesquisa quantitativa e qualitativa. São Paulo: Ed Thomson.

Athayde, M. R. C. (1996). Gestão de trabalho e modernidade. Questões para a engenharia de produção. Tese de doutorado, Universidade Federal do Rio de Janeiro, RJ.

Borges, L. H. (2010). Trabalho de caixa bancário, saúde mental e lesão por esforço repetitivo. In D. M. R. Glina, \& L. E. Rocha. Saúde mental no trabalho: da teoria à prática (pp. 271-301). São Paulo: Roca.

Bruno, W. P. (2011). Bancários não são máquinas. In L. Snelwar. (Org.), Saúde dos bancários (pp. 21-32). São Paulo: Publisher Brasil/Editora Gráfica Atitude.

Dejours, C. (1992). A loucura do trabalho - estudos de psicopatologia do trabalho. São Paulo: Cortez / Oboré.

Dejours, C. (2000). A banalização da injustiça social. Rio de Janeiro: FGV.

Dejours, C. (2004a). Addendum: da psicopatologia à psicodinâmica. In S. Lancman, \& L. I. Sznelwar (Orgs.), Cristophe Dejours: da psicopatologia à psicodinâmica do trabalho. Rio de Janeiro, RJ/ Brasília, DF: Fiocruz/ Paralelo 15. 
Dejours, C. (2004b). Entre sofrimento e reapropriação: o sentido do trabalho. In S. Lancman \& L. I. Sznelwar (Orgs.), Cristophe Dejours: da psicopatologia à psicodinâmica do trabalho. Rio de Janeiro: Fiocruz/ Brasília, DF: Paralelo 15.

Dejours, C. (2004c). Para uma clínica da mediação entre psicanálise e política: a psicodinâmica do trabalho. In S. Lancman, \& L. I. Sznelwar. (Orgs.), Cristophe Dejours: da psicopatologia à psicodinâmica do trabalho. Rio de Janeiro, RJ/ Brasília, DF: Fiocruz/ Paralelo 15.

Dejours, C. (2004d). Epistemologia concreta e ergonomia. In F. Daniellou. A ergonomia em busca de seus princípios: debates epistemológicos. (pp.199-216). São Paulo: Edgard Blücher.

Dejours, C., Dessors, D., \& Derslaux, F. (1993, maio/jun.). Por um trabalho, fator de equilíbrio. RAE - Revista de Administração de Empresas, 33(3), 98-105.

Dejours, C., Abdouchelli, E., \& Jayet, C. (1994). Psicodinâmica do trabalho: contribuições da escola dejouriana à análise da relação prazer, sofrimento e trabalho. São Paulo, SP: Atlas.

Dejours, C., \& Bègue, F. (2010). Suicídio e trabalho: o que fazer? Brasília, DF: Paralelo 15.

Dejours, C., \& Gernet, I. (2011). Trabalho, subjetividade e confiança. In L. Snelwar (Org.), Saúde dos bancários (pp. 33-42). São Paulo: Publisher Brasil/Editora Gráfica Atitude.

Ferreira, M. C., \& Barros, P. C. R. (2002). (In)Compatibilidade trabalho prescrito - trabalho real e vivências de prazersofrimento dos trabalhadores: um diálogo entre a ergonomia da atividade e a psicodinâmica do trabalho. Revista Alethéia, $16,115-128$

Gaulejac, V. de. (2007). Gestão como doença social: ideologia, poder gerencialista e fragmentação social. Aparecida, SP: Idéias e Letras.

Grisci, C. L. I., \& Bessi, V. G. (2004, jul./dez.). Modos de trabalhar e de ser na reestruturação bancária. Sociologias, $6(12), 160-200$

Jinkings, N. (2002). Trabalho e resistência na "fonte misteriosa": os bancários no mundo da eletrônica e do dinheiro. Campinas, SP: Editora da Unicamp; São Paulo: Imprensa Oficial do Estado.

Larangeira, S. M. G. (1997, dez.). Reestruturação produtiva no setor bancário: a realidade dos anos 90. Educação \& Sociedade, 18(61), 110-138. doi: http://dx.doi.org/10.1590/ S0101-73301997000400006

Laville, C., \& Dionne, J. (1999). A construção do saber: manual de metodologia da pesquisa em ciências humanas. Porto Alegre: Editora UFMG/ ArtMed.

Maeno, M. (2011). LER e transtornos psíquicos relacionados ao trabalho: faces de uma mesma moeda. In L. Snelwar (Org.), Saúde dos bancários (pp. 207-230). São Paulo: Publisher Brasil/ Editora Gráfica Atitude.

Máximo, T. A. O. (2009). Super-homem pós-moderno: análise da relação trabalho-saúde de gerentes de bancos públicos e privados. Dissertação de mestrado. Universidade Federal da Paraíba. João Pessoa, PB.

Máximo, T. A. O., Araújo, A. J. S., Zambroni-de-Souza, P. C., \& Alberto, M. F. P. (2011). Exigências nos percursos profissionais de gerentes de banco. Psicologia e sociedade, 23(1), 66-74.

Merlo, A. R. C., \& Barbarini, N. (2002). Reestruturação produtiva no setor bancário brasileiro e sofrimento dos caixas executivos: um estudo de caso. Psicologia \& Sociedade, 14(1), 103-122. doi: http://dx.doi.org/10.1590/S010271822002000100007

Minayo, M. C. S. (2006). O desafio do conhecimento: pesquisa qualitativa em saúde. São Paulo/Hucitec; Rio de Janeiro: Abrasco.

Netz, J. A., \& Mendes, J. M. R. (2006, jan./jun.). O massacre dos trabalhadores bancários e a ação sindical: sobrejornadas, metas excessivas, pressão, medo, práticas gerenciais autoritárias versus práticas preventivas. Boletim da Saúde, 20(1), 25-34.

Rossi, E. Z. (2011). As consequências psíquicas do adoecimento por LER/Dort: o fracasso do processo de reabilitação e a volta ao trabalho. In L. Snelwar (Org.), Saúde dos bancários (pp. 263-286). São Paulo: Publisher Brasil/Editora Gráfica Atitude.

Selligmann-Silva, E. (1994). Desgaste mental no trabalho dominado. Rio de Janeiro: Editora UFRJ/São Paulo: Cortez Editora.

Sennett, R. (1999). A corrosão do caráter: as conseqüências pessoais do trabalho no novo capitalismo. Rio de Janeiro: Ed. Record.

Silva, P. C., \& Merlo, A. R. C.( 2007). Prazer e sofrimento de psicólogos no trabalho em empresas privadas. Psicol.: Ciênc. e Prof., 27(1), 132-147. doi: http://dx.doi.org/10.1590/S141498932007000100011

Soboll, L. A. P. (2010). Organização do trabalho e prática de assédio moral: um estudo sobre trabalho bancário. In D. M. R. Glina \& L. E. Rocha. Saúde mental no trabalho: da teoria à prática (pp. 358-368). São Paulo: Roca.

Souza, L. A. S. (2007). Na ponta da linha das agências: a atividade e a saúde de caixas bancários. Dissertação de mestrado. Programa de Pós-Graduação em Psicologia Social, Universidade Federal da Paraíba, João Pessoa, PB.

Tertre, C. (2011). Bancos e produtividade: entre dinâmica industrial e dinâmica serviçal? In L. Snelwar (Org.), Saúde dos bancários (pp. 83-104). São Paulo: Publisher Brasil/ Editora Gráfica Atitude. 